\title{
Antibiotic-free diet supplemented with live yeasts decreases inflammatory markers in the ileum of weaned piglets
}

\author{
S. Bautista-Marín', K. Escobar-García', C. Molina-Aguilar², G. Mariscal-Landín ${ }^{3}$, A. Aguilera- \\ Barreyro', M. Díaz-Muñoz ${ }^{4}$ \& T.C. Reis de Souza ${ }^{1 \#}$ \\ ${ }^{1}$ Facultad de Ciencias Naturales, Universidad Autónoma de Querétaro, Juriquilla 76230, Querétaro, México \\ ${ }^{2}$ Universidad del Valle de México, Campus Querétaro, Laboratorio Internacional de Investigación sobre el Genoma \\ Humano, Universidad Nacional Autónoma de México Campus Juriquilla 76230, Querétaro, México \\ ${ }^{3}$ CENID-Fisiología Instituto Nacional de Investigaciones Forestales, Agrícolas y Pecuarias, Ajuchitlán 76280, Querétaro, \\ México \\ ${ }^{4}$ Instituto de Neurobiología, Universidad Nacional Autónoma de México Campus Juriquilla 76230, Querétaro, México
}

(Received 23 August 2019; Accepted 18 May 2020; First published online 31 May 2020)

Copyright resides with the authors in terms of the Creative Commons Attribution 4.0 South African License.

See: http://creativecommons.org/licenses/by/4.0/za Condition of use: The user may copy, distribute, transmit and adapt the work, but must recognise the authors and the South African Journal of Animal Science.

\begin{abstract}
Emerging bacterial resistance to antibiotics increases the need for effective alternatives to control intestinal inflammation and thus gut disorders in piglets. This study evaluated the effects of including Saccharomyces cerevisiae (strain 1026) and Saccharomyces boulardii (CNCM I-1079) as antibiotic alternatives in the starter diets of pigs on the concentrations of ileal inflammatory markers (nuclear factor-kB (NF-kB)), interleukin-6 (IL-6), tumour necrosis factor alpha (TNF- $\alpha$ ), and interleukin-12 subunit p40 (IL12p40), and villus height. Forty piglets were assigned to four experimental diets, namely basal diet (C-), basal diet with antibiotics $\left(\mathrm{C}_{+}\right)$, basal diet with $\mathrm{S}$. cerevisiae $(\mathrm{Sc})$, and basal diet with $\mathrm{S}$. boulardii (Sb). At 7 and 14 days post weaning, five piglets per diet group were euthanized to quantify the inflammatory markers and to measure villus height. The $\mathrm{C}$ - group exhibited the highest concentration of inflammatory markers and the most atrophied villi. The Sc group had intermediate values for both variables. The $\mathrm{C}+$ group had the lowest values for inflammatory markers and the highest villus height was similar to that of the Sb group, which showed low concentrations of inflammatory markers, although not so low as those of the $\mathrm{C}+$ group. Both yeasts could be used as antibiotic alternatives to reduce the use of antibiotics in pig starter diets. However, S. boulardii CNCM I-1079 supplementation controls inflammation and preserves intestinal mucosa more effectively than S. cerevisiae strain 1026.
\end{abstract}

Keywords: cytokines, pigs, probiotic, Saccharomyces, weaning

"Corresponding author: tercia@uaq.mx

\section{Introduction}

Weaning is one of the most stressful events in a piglet's life and can contribute to intestinal and immune system dysfunction, resulting in intestinal bacterial proliferation (Dirkzwager et al., 2005). This increase in bacteria can reduce the health, growth, and feed intake of pigs, particularly during the first week after weaning (Campbell et al., 2013). Weaning of piglets is associated with an early and transient response in the gene expression of inflammatory cytokines in the gut (Pié et al., 2004). The synthesis and release of cytokines are stimulated by bacteria, viruses, parasites, fungi, and numerous non-infectious stimulants such as allergens, transient anorexia, and other proinflammatory cytokines, including interleukin-1 (IL-1), tumour necrosis factor alpha (TNF- $\alpha$ ), and interleukin-6 (IL-6), which induce the production of acute phase proteins (McCracken et al., 1999; Naugler \& Karin, 2013). Interleukin 12 subunit p40 (IL-12p40) increases during chronic inflammation (Trinchieri et al., 2003; Abdi et al., 2014; Zundler \& Neurath, 2015).

Bacterial antigens in the intestinal lumen generate an acute inflammatory response through the action of proinflammatory cytokines, which activate a signalling cascade, leading to the release of nuclear factor- $\mathrm{KB}$ (NF-KB), which translocates to the nucleus and serves as a transcription factor for the synthesis of IL-6 and TNF- $\alpha$ (Lawrence, 2009; Fernández-Jiménez et al., 2014). The proinflammatory cytokine TNF- $\alpha$ acts as an acute inflammation mediator that increases the production of IL-1 and IL-6 (Sánchez-Muñoz et al., 2008). The inflammation mediated by IL-12p40 is activated through the Janus kinase/signal transducers and 
activators of transcription (JAK/STAT), in which it is dimerised and phosphorylated, allowing its translocation to the nucleus where IL-12p40 is transcribed.

Early control of intestinal inflammation is important for the effective management of post-weaning gut disorders in piglets (Pié et al., 2004). Traditionally, these disorders have been controlled with various methods including the administration of antibiotics. However, with the recent rise in bacterial resistance to antibiotics, several countries have restricted the use of antibiotics in animal feed. Recent research has focused on animal nutrition, aiming to find alternatives to antibiotics (Nyachoti et al., 2006; Stein \& Kil, 2006). One suggested alternative is the use of probiotics, which are defined by the World Health Organization (WHO) as live microorganisms, which, when administered in adequate amounts, confer health benefits to their host, and have potential to improve human health (WHO, 2001).

Probiotic yeasts act by interrupting the signalling pathways involved in the inflammatory response (Czerucka \& Rampal, 2002; McFarland, 2010), thereby helping to restore intestinal balance and the health of the piglets. Saccharomyces cerevisiae and Saccharomyces boulardii are probiotic yeasts that affect their hosts differently, owing to their own morphophysiological differences (Hudson et al., 2016). Saccharomyces cerevisiae has been used for many years as a probiotic in pigs owing to its effect on growth and reproductive performance and the reduction of morbidity and mortality, particularly in young animals (Pérez-Sotelo et al., 2005). Saccharomyces boulardii is a nonpathogenic probiotic yeast that has been used for decades to protect against intestinal injury and inflammation (Chen et al., 2013). Many studies have evaluated the effects of $S$. cerevisiae on the reduction of intestinal inflammation in pigs challenged with pathogens (e.g. Martins et al., 2011; Trevisi et al., 2016). Saccharomyces boulardii has also been evaluated in several studies, mostly conducted in humans and rodents (Dalmasso et al., 2006; Sougioultzis et al., 2006; Martins et al., 2010).

The aim of the present study was to determine whether S. boulardii strain CNCM I-1079 and S. cerevisiae strain 1026 could be used as alternatives to antibiotics in the starter diets of piglets. Supplementation of these yeasts in starter diets for piglets was hypothesized to diminish the concentration of inflammatory markers (NF-kB, IL-6, TNF- $\alpha$, and IL-12p40) in ileal tissue and improve villus height. It was further hypothesized that S. boulardii strain CNCM I-1079 would have greater efficacy than S. cerevisiae strain 1026.

\section{Material and Methods}

All experimental procedures were reviewed and approved by the Bioethical Committee of the Faculty of Natural Sciences of the Autonomous University of Queretaro (approval number: 43FCN2016). Piglets were handled according to the guidelines of the Mexican Official Norm NOM-062-ZOO-1999 for production, care, and use of animals for experimentation (Diario Oficial de la Federación, 2001) and guidelines of the International Guiding Principles for Biomedical Research Involving Animals (CIOMS-ICLAS, 2012).

In this study the authors utilized forty hybrid piglets (Genetiporc, Fertilis $25 \times$ G Performance 8), weaned at $20 \pm 1.6$ days and weighing $6.5 \pm 0.3 \mathrm{~kg}$, and four experimental diets. The weaned piglets were assigned to one of the four diets according to litter origin and bodyweight, and were immediately housed in two pens per diet, each with five piglets, making a total of 10 piglets per diet. To prepare the four experimental diets, first the authors formulated a basal diet without antibiotics or live yeast (Table 1) or negative control (C-). Subsequently, the authors added $0.05 \%$ of antibiotics, $0.8 \%$ of $S$. cerevisiae, and $0.1 \%$ of $S$. boulardii to the basal diet at the expense of maize to establish the three other diets, namely positive control (C+), Sc and Sb, respectively. The antibiotic that was used was LincoSpectin (lincomycin + spectinomycin 1:1) from Zoetis (Parsippany, NJ, USA); the S. cerevisiae was Yea-Sacc ${ }^{\circledR}$ strain 1026 from Alltech (Nicholasville, KY, USA); and the S. boulardii was Levucell SB ${ }^{\circledR}$, CNCM I-1079 from Lallemand Animal Nutrition (Montréal, Canada). The doses of yeast in diets were recommended by the manufacturer.

Pens were equipped with feeders and nipple drinkers in an environmentally controlled weaning room $\left(30{ }^{\circ} \mathrm{C}\right.$ and $28 \pm 2$ during the first and second post-weaning weeks, respectively). The piglets had free access to water and were fed thrice per day at $8 \mathrm{~h} 00,12 \mathrm{~h} 00$, and $16 \mathrm{~h} 00$. Faecal consistency was monitored. Piglets were individually weighed at 0,7 , and 14 days post weaning (PWD), and the average daily gain (ADG) per postweaning week was calculated. Average daily gain and faecal consistency were considered indicators of pig health.

All piglets of one pen per diet were euthanized at 7 PWD, and the remaining five piglets per diet were euthanized at 14 PWD. Piglets were tranquilized with $20 \mathrm{mg} / \mathrm{kg}$ azaperone (Sural ${ }^{\circledR}$, Chinoin, Mexico City, Mexico) and then euthanized with an overdose of sodium pentobarbital (Pisabental ${ }^{\circledR}$, PiSA Agropecuaria, Hidalgo, Mexico). Ileal tissue sections $(10 \mathrm{~cm}$ ) were sampled from $5 \mathrm{~cm}$ before the ileocecal valve, gently washed with distilled water, and then dissected and fixed in $10 \%$ buffered formalin solution.

lleal sections were embedded in paraffin, cut into $5-\mu \mathrm{m}$ slices, and stained with haematoxylin-eosin. To determine the average villus height (from apex-base) and crypt depth (from the villi base to the bottom of 
the crypt) (Nabuurs et al., 1993; Makkink et al., 1994), 10 villi were examined under an optical microscope with a $10 \times$ objective (Primo Star, Carl Zeiss, Oberkochen, Germany) and analysed using ZEN software (Carl Zeiss, Jena, Germany).

The other $5-\mu \mathrm{m}$ slices were used to quantify NF-KB, IL-6, TNF- $\alpha$, and IL-12p40 using an immunofluorescence technique adapted from that of Rivera-Zavala et al. (2017). Ileal slices were deparaffinized for 2 hours at $60{ }^{\circ} \mathrm{C}$ in a dry-heat oven and then rehydrated in $100 \%$ xylol $(10 \mathrm{~min}), 100 \%$ ethanol (5 min), 96\% ethanol (5 $\mathrm{min}), 80 \%$ ethanol $(5 \mathrm{~min})$, and deionized water (10 $\mathrm{min}$ ), in this order. Ileal slices were then soaked in saline-sodium citrate buffer concentrate 1× (Sigma-Aldrich, Saint Louis, MO, USA) in a water bath at $80^{\circ} \mathrm{C}$ for $25 \mathrm{~min}$. Then, ileal slices were blocked with $1 \%$ non-fat milk for 1 hour, washed three times for 5 min each with $0.05 \%$ TRIS-buffered saline plus Tween (TBST), and incubated for 2 hours at $4{ }^{\circ} \mathrm{C}$ with the following antibodies diluted in TBST: i) rabbit anti NKIRAS2 (MBS 631230) (Mybiosource, San Diego, CA, USA) at 1:50 dilution; ii) rabbit anti TNF- $\alpha$ (ab 6671) (Abcam, Cambridge, MA, USA) at 1:200 dilution; iii) rabbit anti IL-12p40 (ab 106270) (Abcam) at 1:100 dilution; and iv) incubated rabbit anti IL-6 (ab 6672) (Abcam) for 16 hours at 1:400 dilution.

Ileal slices were then washed three times for 5 min each with $0.05 \%$ TBST buffer and incubated for 2 hours with the secondary antibody Alexa Fluor 488 chicken anti-rabbit IgG $(H+L)(A-21441)$ (Invitrogen Molecular Probes Inc., Eugene, OR, USA) at 1:500 dilution. The intensity of the fluorescence (arbitrary fluorescence units (AFU)) was evaluated with the positive (primary and secondary antibodies) and negative (secondary antibodies only) controls considering the same size of area in ileal tissue under both conditions (Rivera-Zavala et al., 2017). For the analysis, 10 intestinal villi per piglet were visualized and photographed at 40x magnification (Olympus CX31, Olympus Instruments, Tokyo, Japan) and then 10 sections from each intestinal villi were selected per photo to obtain 100 measurements per piglet. Fluorescence was visualized and measured with a fluorescence microscope (Eclipse E600, Nikon, Minato, Japan) and Image-Pro Plus version 6.1 (Media Cybernetics, Silver Spring, MD, USA).

Table 1 Ingredients and chemical percentage composition of the basal diet (as-fed basis)

\begin{tabular}{lrlc}
\hline Ingredients & $\%$ & Chemical composition $\infty$ & \\
\hline Maize & 47.05 & Dry matter, \% & 89.50 \\
Soybean meal & 15.00 & Crude protein, \% & 21.80 \\
Fish Menhaden meal & 9.23 & Neutral detergent fibre, \% & 12.30 \\
Whey dried & 24.69 & Metabolizable energy, kcal/kg & 3,300 \\
Maize oil & 1.49 & Lysine, \% & 1.70 \\
Lysine $_{\text {Aminogut }}{ }^{1}$ & 0.25 & Methionine, \% & 0.49 \\
Threonine $_{\text {Tryptophan }}$ & 0.80 & Tryptophan, \% & 0.28 \\
Dicalcium phosphate $^{\text {Vitamins }}{ }^{2}$ & 0.10 & Threonine, \% & 1.05 \\
Minerals $^{3}$ & 0.05 & & \\
Biocoline $_{\text {Sodium butyrate }}$ & 0.90 & & \\
& 0.08 & & \\
\hline
\end{tabular}

${ }^{1}$ Aminogut: L-glutamine and L-glutamic acid (1:1), (Ajinomoto, Japan)

${ }^{2}$ Vitamins per $\mathrm{kg}$ of diet, A: 10,200 UI, D: 1980 UI, E: $60 \mathrm{UI}, \mathrm{K}: 1.20 \mathrm{mg}$, biocoline: $38 \mathrm{mg}$; niacin: $36 \mathrm{mg}$, pantothenate: $17 \mathrm{mg}$, riboflavin: $7.2 \mathrm{mg}$, $\mathrm{B}_{12}: 38 \mu \mathrm{g}$, thiamine: $0.3 \mathrm{mg}$, pyridoxine: $0.31 \mathrm{mg}$, biotin: $0.08 \mathrm{mg}$, folate: $0.75 \mathrm{mg}$

${ }^{3}$ Minerals per $\mathrm{kg}$ of diet, copper: $14.4 \mathrm{mg}$, iodine: $800 \mathrm{mg}$, iron: $105 \mathrm{mg}$, manganese: $36 \mathrm{mg}$, selenium: $0.3 \mathrm{mg}$, zinc: 144 $\mathrm{mg}$

Average daily gain, villus height, crypt depth, and inflammatory marker concentrations were analysed using a completely randomized design, and each piglet was considered an experimental unit (Steel \& Torrie, 1997). ANOVA was used to analyse the differences between diet groups (SAS, 1994). Means were compared with the Student-Newman-Keuls test using the GLM procedure of SAS, and differences were considered statistically significant at $P<0.05$. 


\section{Results and Discussion}

During the first week post weaning, no differences $(P>0.05)$ were observed in ADG (Table 2) However, in the second post-weaning week, the highest ADG $(P<0.001)$ was observed for the animals fed the $\mathrm{C}+$ diet compared with the piglets fed the other diets. The ADG was similar between piglets fed the Sc and $\mathrm{Sb}$ diets, and the lowest for those in the $\mathrm{C}$ - group compared with the other groups $(P<0.001)$ (Table 2$)$.

Table 2 Mean ( \pm SEM) average daily gain $(\mathrm{g})$ of four starter diets with or without probiotics for piglets

\begin{tabular}{|c|c|c|c|c|c|c|}
\hline & \multicolumn{4}{|c|}{ Experimental diets } & \multirow{2}{*}{$P$-value } & \multirow{2}{*}{ SEM } \\
\hline & $\mathrm{C}+$ & Sc & $\mathrm{Sb}$ & C- & & \\
\hline ADG1 & 130 & 67 & 10 & 63 & 0.1834 & 18.58 \\
\hline ADG2 & $300^{a}$ & $214^{b}$ & $211^{\mathrm{b}}$ & $157^{\circ}$ & 0.0001 & 7.34 \\
\hline
\end{tabular}

ADG1 and ADG2: average daily gain in 1 and 2 post-weaning weeks; C+: diet with antibiotics; Sc; diet with Saccharomyces cerevisiae; Sb; diet with Saccharomyces boulardii; C-: diet without antibiotics or probiotics; $P$ : statistical significance; a,b,c Row means with different superscripts differ significantly at $P<0.05$; SEM: standard error of mean

Faecal consistency indicated that all piglets had mild diarrhoea throughout the experimental period (14 days). However, no animals required medication, nor were any euthanized for health reasons.

At 7 and 14 PWD the longest villi were observed in piglets fed the $\mathrm{Sb}$ and $\mathrm{C}+$ diets, while those fed the Sc diet had intermediate villus height. The shortest villi were observed in animals fed the C- diet $(P<0.001)$ (Figure 1). Pronounced villous atrophy was observed in the piglets fed the $\mathrm{C}$ - diet because they were $55 \%$ and $57 \%$ (at 7 and 14 days post weaning, respectively) shorter than the villi of piglets fed the other diets (Figure 1). Regarding crypt depth at 7 and 14 PWD, no differences were observed $(P>0.05)$ among diets. However, on day 7 after weaning, there was a tendency $(P<0.085)$ for animals to have deeper crypts when fed the $\mathrm{Sb}$ diet (122 and $104 \mu \mathrm{m}$ for $\mathrm{Sb}$ and other treatments, respectively).

The concentrations of NF-KB, IL-6, TNF- $\alpha$, and IL-12p40 in the ileal villi of weaned piglets were affected $(P<0.001)$ by diet at 7 and 14 PWD (Figures $2-5)$. The piglets fed the $C$ - diet had the highest concentrations of all inflammatory markers. Those fed the Sc diet showed intermediate concentrations, and the $\mathrm{C}+$ and $\mathrm{Sb}$ groups had the lowest concentrations $(P<0.001)$ (Figures $2-5)$. There was the highest AFU signal for IL-12p40 compared with the other inflammatory markers in piglets fed all experimental diets, but particularly in those fed the C- diet (Figure 5). 


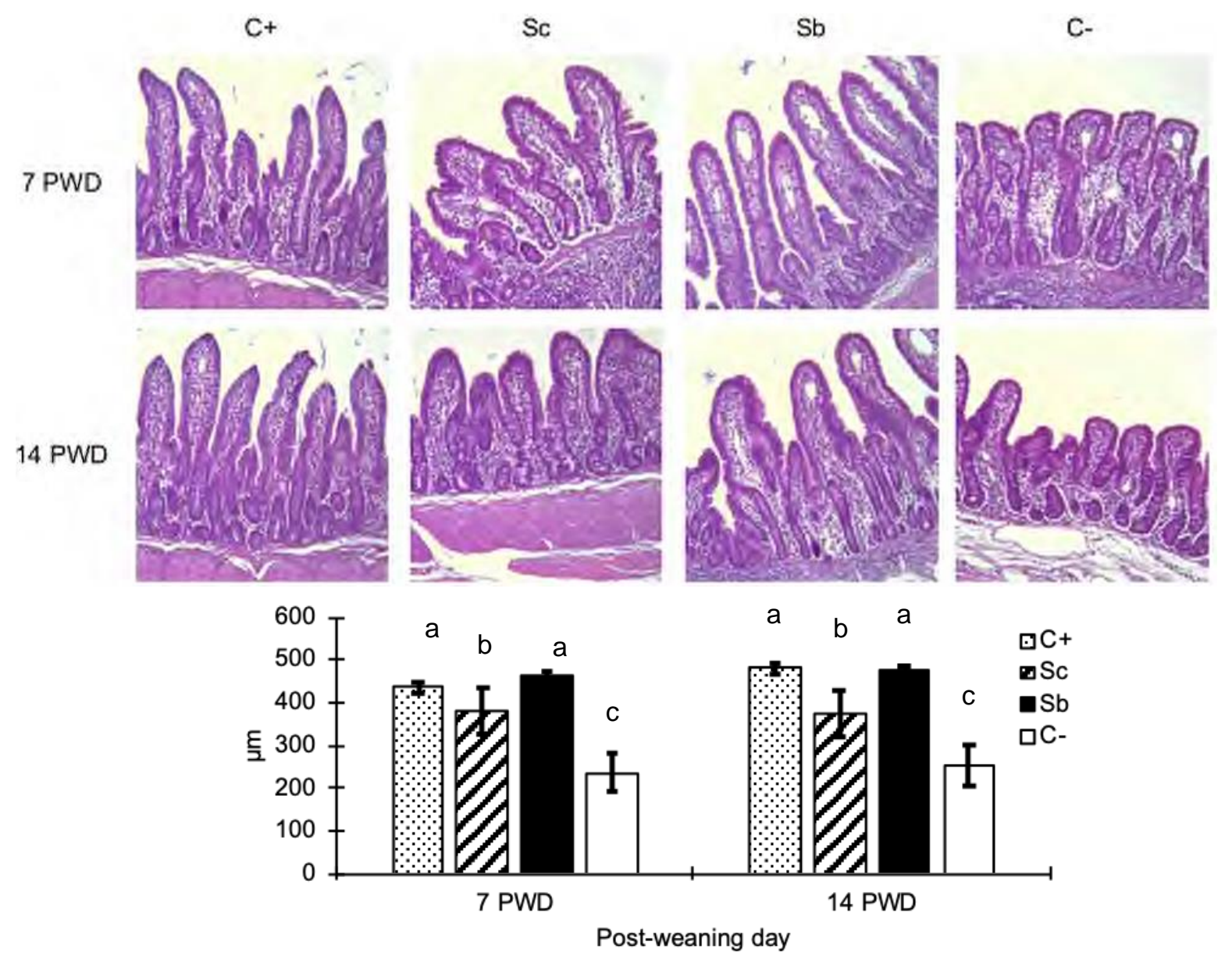

Figure 1 Haematoxylin-eosin staining of villi at 7 and 14 days post weaning (PWD).

Bars with different letters differ significantly at $P<0.001$. Data are presented as mean $\pm \mathrm{SD}$ 


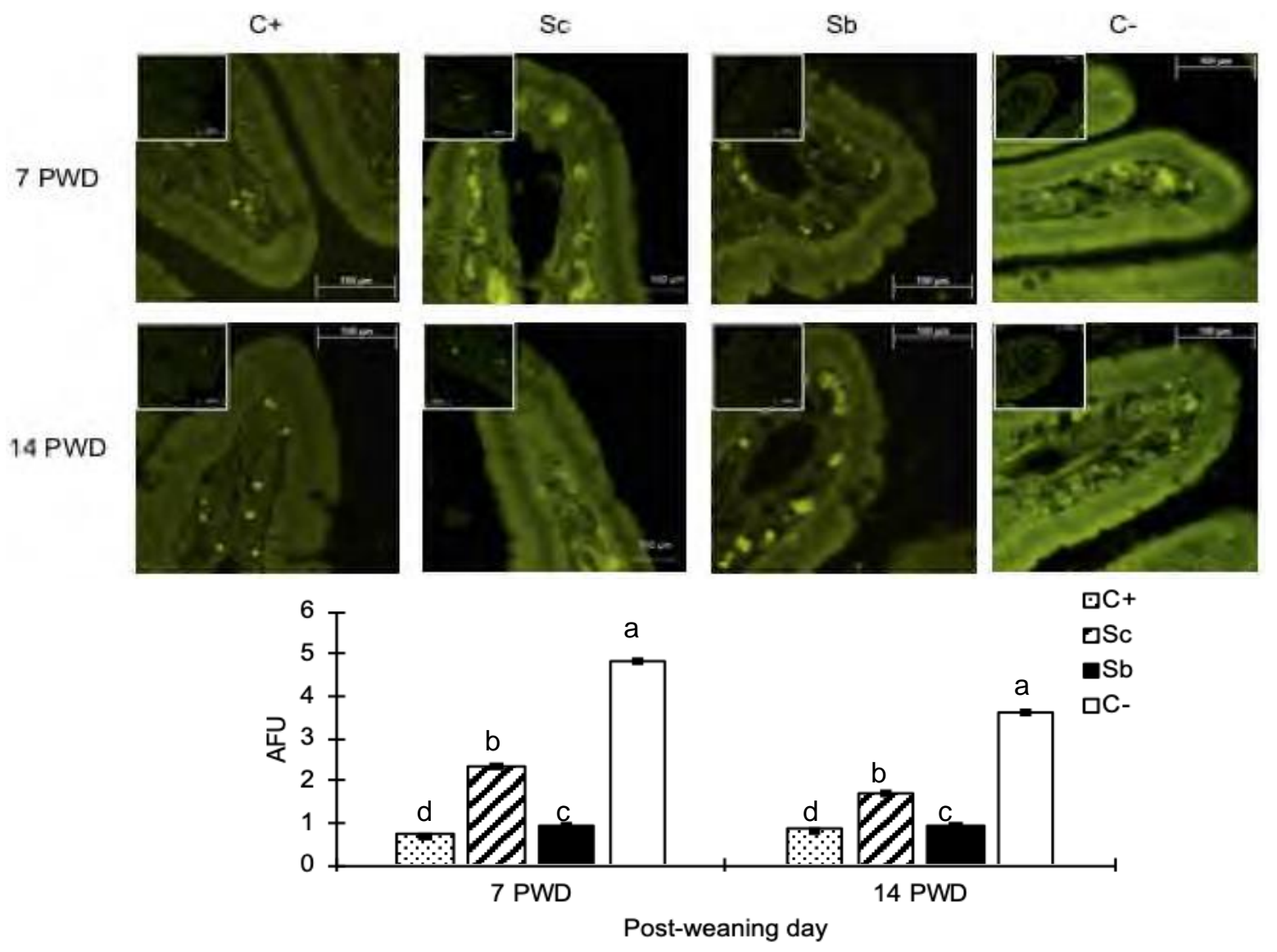

Figure 2 Concentration of NF-KB in the ileum of piglets fed with different experimental diets highlighted by immunofluorescence staining

The inset boxes show representatives of the controls without the primary antibody. Bars with different letters differ significantly at $P<0.001$. Data are presented as mean \pm SD 




Figure 3 Concentration of IL-6 in the ileum of piglets fed different experimental diets highlighted by immunofluorescence staining

The inset boxes show representatives of the controls without the primary antibody. Bars with different letters differ significantly at $P<0.001$. Data are presented as mean $\pm \mathrm{SD}$ 


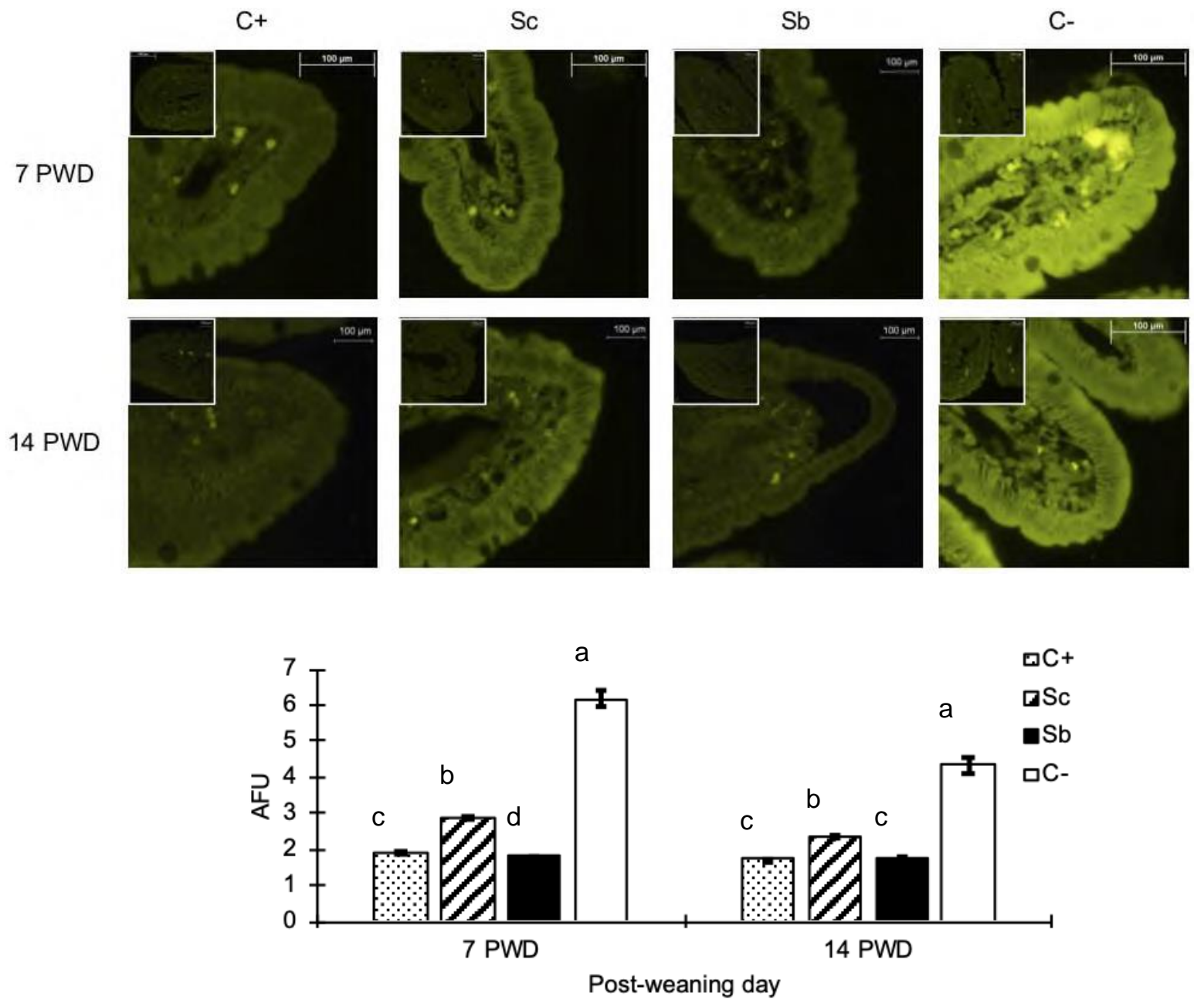

Figure 4 Concentration of TNF- $\alpha$ in the ileum of piglets fed different experimental diets highlighted by immunofluorescence staining

The inset boxes show representatives of the controls without the primary antibody. Bars with different letters differ significantly at $P<0.001$. Data are presented as mean $\pm \mathrm{SD}$ 


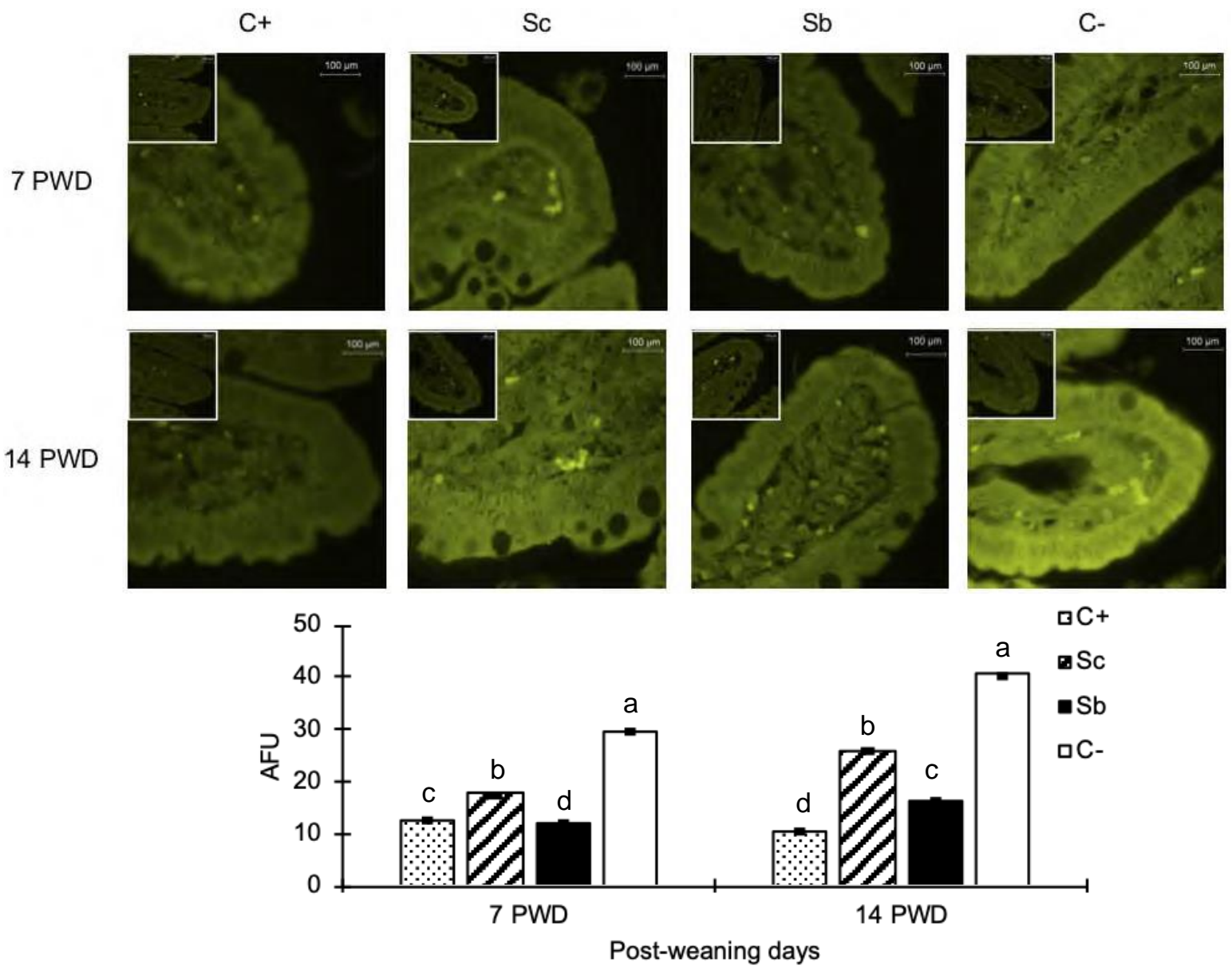

Figure 5 Concentration of IL-12p40 in the ileum of piglets fed different experimental diets highlighted by immunofluorescence staining

The inset boxes show representatives of the controls without the primary antibody. Bars with different letters differ significantly at $P<0.001$. Data are presented as mean \pm SD

The low ADG observed in the first week after weaning can be explained by the stress of weaning, which provokes deleterious physiological and immunological changes and generalized poor development (Campbell et al., 2013). In the second post-weaning week, the piglets in the $\mathrm{C}_{+}, \mathrm{Sc}$, and Sb diet groups had an ADG within the parameters usually reported for piglets of the same age group on the experimental farm (Escobar et al., 2015), while those in the C- diet group were below these parameters. Weight gain and faecal consistency indicated that the animals were in good health, in accordance with the post-weaning phase and the diet consumed. These issues were observed to be at their worst in animals fed antibiotic-free diets without yeast (C-). Moreover, the highest daily weight gain (Table 2) was observed during the second week post weaning week in piglets fed the diet with antibiotics $\left(\mathrm{C}_{+}\right)$, which was probably owing to the growth promoter effect of the antibiotics (Cromwell, 2002; Gaskins et al., 2002). However, in the present study, the yeasts did not show a similar effect to antibiotics to stimulate growth performance during the second week post weaning, and the animals in the Sc and Sb groups demonstrated good levels of recovery in this week. However, further studies are required with a greater number of animals to elucidate fully the effect of the yeast, especially $S$. boulardii, on piglet performance.

The findings of the present study corroborate these of previous observations (Czerucka \& Rampal, 2002; Buts, 2009; McFarland, 2010; Palma et al., 2015), in that the highest concentrations of inflammatory markers were observed in animals fed diets without antibiotics or yeasts (C-). This inflammatory process affected villus height because the animals fed the $\mathrm{C}$ - diet had the shortest villi at 7 and 14 PWD, as reported 
by Pié et al. (2004) and Nyachoti et al. (2006). These authors found that weaning coupled with diets without antibiotics or probiotics caused intestinal dysbiosis that changed the intestinal environment and led to an inflammatory response that caused cell death, resulting in atrophied villi and an increase in apoptosis and a decrease in the replacement of enterocytes within the crypts (Jiang et al., 2015).

Previous work had suggested that the results from the immunological markers in the ileum confirmed that cytokines play a central role in cell immunity and participate in maintaining tissue integrity (Pié et al., 2004). Changes in the concentrations of intestinal cytokines were expected for weaning piglets because the abrupt modifications in dietary components and stress factors experienced during this stage lead to important morphological and functional adaptations in the intestine (McCracken et al., 1999; Pié et al., 2004). The imbalance caused by changes in the intestinal mucosa induces an inflammatory process that activates NF-KB and subsequent production of proinflammatory cytokines (Czerucka \& Rampal, 2002; Buts, 2009; McFarland, 2010; Palma et al., 2015), and villous atrophy occurs (Stein \& Kil, 2006; Lallès et al., 2007). These responses are accentuated when newly weaned animals are fed antibiotic-free diets (Jiang et al., 2015).

Dietary supplementation of antibiotics or yeasts $\left(\mathrm{C}_{+}, \mathrm{Sc}\right.$, and $\left.\mathrm{Sb}\right)$ modulated the production of inflammatory markers, which were maintained at low concentrations (Liu et al., 2018), and increased villus height. The downregulation of cytokines by antibiotics was confirmed by the current results, since all measured markers decreased in piglets fed the $\mathrm{C}+$ diet. The suppressant effect of antibiotics on the ileal bacterial population (Cromwell, 2002; Gaskins et al., 2002) probably inhibited the signalling pathway that induces the release of NF-KB, which was slightly marked by the primary antibody used in the current study for immunofluorescence staining (Figure 2). IL-6 concentration also decreased because the activation of NF$\mathrm{KB}$ is required for its synthesis (Saavedra et al., 2011). Furthermore, the antibiotics in the C+ diet decreased IL-12p40 synthesis, and thus concentration, probably owing to the reduced stimulus generated by bacterial pathogens and to the inhibition of the pathway mediated by JAK/STAT (Trinchieri et al., 2003). Therefore, dietary antibiotic supplementation regulates inflammatory response and indirectly protects the intestinal mucosa, decreasing the detrimental effects of weaning on the intestinal villi (Stein \& Kil, 2006; Thacker, 2013). This finding was further evidenced by the longer villi observed in piglets fed the C+ diet, avoiding villous atrophy.

The control of inflammatory markers in ileal mucosa owing to $S$. cerevisiae strain 1026 was expected because $S$. cerevisiae-supplemented diets modulate signalling pathways, preventing NF-KB translocation to the nucleus and inhibiting the expression of genes involved in IL-6 and TNF- $\alpha$ synthesis (Martins et al., 2011; Zanello et al., 2011). Regarding IL-12p40, S. cerevisiae probably inhibits both NF-KB and the JAK/STAT complex, preventing IL-12p40 synthesis, and thereby reducing inflammation. The regulation of inflammation resulting from the action of $S$. cerevisiae strain 1026 in the ileum was sufficient to avoid considerable villous atrophy at 7 and 14 PWD. The presence of S. cerevisiae strain 1026 in the intestine likely promoted competitive bacterial exclusion, short-chain fatty acid production, and growth factor synthesis leading to environmental conditions that are less damaging to the intestinal mucosa, limiting cell loss, and favouring villous and mucosal integrity (Kiarie et al., 2012).

The current results support the assertion that $S$. boulardii can modulate the levels of intestinal cytokines and reduce villous atrophy (Czerucka \& Rampal, 2002). Piglets fed diets supplemented with $S$. boulardii strain CNCM I-1079 (i.e. Sb) had high levels of inflammatory markers that were comparable with those of piglets fed the C+ diet. They also had reduced NF-KB and IL-6 concentrations at 7 and 14 PWD. The immunomodulatory effect of $S$. boulardii strain CNCM I-1079 at the intestinal level is due to the inhibition of signalling pathways like NF-KB, JAK/STAT complex, and mitogen-activated protein kinase pathways, causing this yeast to function as an "immunobiotic" by inhibiting the synthesis of proinflammatory cytokines (Pothoulakis, 2009; Martins et al., 2013). These findings agree with those of previous studies (Sougioultzis et al., 2006; Czerucka et al., 2007), which reported a decrease in TNF- $\alpha$ and IL-6 expression in animals fed diets supplemented with this yeast. Another benefit observed with the addition of $S$. boulardii strain CNCM I1079 to antibiotic-free diets was the control of chronic inflammation associated with the increase in IL-12p40 (López-Hernández et al., 2015) at 14 days post weaning. This was $143 \%$ and $278 \%$ of that in Sc and C- fed piglets, respectively. The efficiency of $S$. boulardii strain CNCM I-1079 in controlling acute and chronic intestinal inflammation observed in the present study had a positive effect on villus morphology in the Sb-fed piglets. This was a similar effect to that of the antibiotics in the $\mathrm{C}+$ diet, indicating that $S$. boulardii strain CNCM I-1079 is very efficient at preserving intestinal integrity, as reported in previous studies (Bontempo et al., 2006). This is probably owing to polyamine production, which favours epithelial cell renewal, enterocyte differentiation and maturation, allowing villi to recover (Budiño et al., 2005; McFarland, 2010; Rajput et al., 2013; Liu et al., 2018).

The differences observed between piglets fed $\mathrm{Sc}$ and $\mathrm{Sb}$ diets in the present study can probably be explained by the metabolic and physiological differences between $S$. boulardii and $S$. cerevisiae. These 
differences result in different behaviours, particularly in temperature resistance and the response to stress generated by the gastric acid environment, which are important characteristics for a microorganism to function as a probiotic (Hudson et al., 2016). In addition, several factors could influence yeast probiotic effects, such as cell wall thickness, resistance to $\mathrm{pH}$ changes, gastrointestinal tract viability, and the ability to compete with other intestinal microorganisms (Fietto et al., 2004; Edwards-Ingram et al., 2007; Hudson et al., 2016).

\section{Conclusions}

Inclusion of both S. cerevisiae strain 1026 and S. boulardii CNCM I-1079 in antibiotic-free diets can improve intestinal health in the post-weaning period. Furthermore, S. boulardii CNCM I-1079 was able to maintain a healthy villus height and helped to reduce the inflammatory response of the measured proinflammatory markers, mainly in the second week after weaning. Its effects were similar to those of the antibiotic-supplemented diet. Therefore, S. boulardii CNCM I-1079 has high potential to be used as a feed additive in antibiotic-free diets. However, further studies are necessary to elucidate the molecular mechanism underlying the regulation of intestinal immunity and the function of $S$. boulardii.

\section{Acknowledgments}

This research was supported by Consejo Nacional de Ciencia y Tecnología (CONACYT), grant number CB-201201000000000179898 and Fondo para el Fortalecimiento de la Investigación UAQ-2018 grant number FNV201807. The authors are grateful to Miriam Martínez Olivo, Leticia Castillo Heredia, and Olivia Vázquez Martínez for technical and farm support.

\section{Authors' Contributions}

Conceptualization, TRS and SBM; methodology, TRS, CMA and SBM; validation, TRS and GML; formal analysis, SBM and KEG; investigation, SBM and GML; resources, TRS and MDM; writing original draft preparation, SBM, TRS and KEG; writing, review and editing, SBM, TRS, CMA, GML, KEG and AAB; visualization, SBM and TRS; supervision, TRS; project administration, TRS; funding acquisition, TRS.

\section{Conflict of Interest Declaration}

The authors declare that they have no conflicts of interest.

\section{References}

Abdi, K., Singh, N.J., Spooner, E., Kessler, B.M., Radaev, S., Lantz, L., Xiao, T.S., Matzinger, P., Sun, P.D. \& Ploegh, H.L., 2014. Free IL-12p40 monomer is a polyfunctional adapter for generating novel IL-12-like heterodimers extracellularly. J. Immunol. 192, 6028-6036. DOI: 10.4049/jimmunol.1400159

Bontempo, V., Di Giancamillo, A., Savoini, G., Dell'Orto, V. \& Domeneghini, C., 2006. Live yeast dietary supplementation acts upon intestinal morpho-functional aspects and growth in weanling piglets. Anim. Feed Sci. Technol. 129, 224-236. DOI: 10.1016/j.anifeedsci.2005.12.015

Budiño, F.E., Thomaz, M.C., Kronka, R.N., Nakaghi, L.S.O., Tucci, F.M., Fraga, A.L., Scandolera, A.J. \& Huaynate, R.A.R., 2005. Effect of probiotic and prebiotic inclusion in weaned piglet diets on structure and ultra-structure of small intestine. Braz. Arch. Biol. Technol. 48, 921-929. DOI: 10.1590/S1516-89132005000800008

Buts, J.P., 2009. Twenty-five years of research on Saccharomyces boulardii trophic effects: Updates and perspectives. Dig. Dis. Sci. 54,15-18. DOI: 10.1007/s10620-008-0322-y

Campbell, J.M., Crenshaw, J.D. \& Polo, J., 2013. The biological stress of early weaned piglets. J. Anim. Sci. Biotechnol. 4, 19-22. DOI: 10.1186/2049-1891-4-19

Chen, X., Yang, G., Song, J.H., Xu, H., Li, D., Goldsmith, J., Zeng, H., Parsons-Wingerter, P., Reinecker, H-C. \& Kelly, C.P. 2013. Probiotic yeast inhibits VEGFR signaling and angiogenesis in intestinal inflammation. PLoS ONE 8,e64227. DOI: 10.1371/journal.pone.0064227

CIOMS-ICLAS, 2012. Council for International Organization of Medical Sciences and The International Council for Laboratory Animal Science. International Guiding Principles for Biomedical Research Involving Animals. https://cioms.ch/wp-content/uploads/2017/01/ResarchInvolvingAnimals.pdf https://olaw.nih.gov/sites/default/files/Guiding_Principles_2012.pdf Accessed 02 February 2016

Cromwell, G.L., 2002. Why and how antibiotics are used in swine production. Anim. Biotechnol. 13, 7-27. DOI: 10.1081/ABIO-120005767

Czerucka, D. \& Rampal, P., 2002. Experimental effects of Saccharomyces boulardii on diarrheal pathogens. Microbes Infect. 4, 733-739. DOI: 10.1016/S1286-4579(02)01592-7

Czerucka, D., Piche, T. \& Rampal, P., 2007. Review article: Yeast as probiotics - Saccharomyces boulardii. Aliment. Pharmacol. Ther. 26, 767-778. DOI: 10.1111/j.1365-2036.2007.03442.x

Dalmasso, G., Loubat, A., Dahan, S., Calle, G., Rampal, P. \& Czerucka, D., 2006. Saccharomyces boulardii prevents TNF- $\alpha$ induced apoptosis in EHEC-infected T84 cells. Res. Microbiol. 157, 456-465. DOI: 10.1016/j.resmic.2005.11.007

Diario Oficial de la Federación, 2001. Norma Oficial Mexicana NOM-062-ZOO-1999, Especificaciones técnicas para la producción, cuidado y uso de los animales de laboratorio. Diario Oficial de la Federación. México, D.F. 
https://www.gob.mx/cms/uploads/attachment/file/203498/NOM-062-ZOO-1999_220801.pdf._ Accessed 02 February 2016

Dirkzwager, A., Veldman, B. \& Bikker, P.A., 2005. A nutritional approach for the prevention of post-weaning syndrome in piglets. Anim. Res. 54, 231-236. DOI: 10.1051/animres:2005013

Edwards-Ingram, L., Gitsham, P., Burton, N., Warhurst, G., Clarke, I., Hoyle, D., Oliver, S.G. \& Stateva, L., 2007. Genotypic and physiological characterization of Saccharomyces boulardii, the probiotic strain of Saccharomyces cerevisiae. Appl. Environ. Microbiol. 73, 2458-2467. DOI: 10.1128/AEM.02201-06

Escobar, G.K., Reis de Souza, T.C., Mariscal, L.G., Aguilera, B.A., Bernal, S.M.G. \& Gómez, S. J.G., 2015. Microbial fermentation patterns, diarrhea incidence, and performance in weaned piglets fed a low protein diet supplemented with probiotics. Food Nutr. Sci. 5, 1776-1786. DOI: 10.4236/fns.2014.518191

Fernández-Jiménez, N., Castellanos-Rubio. A., Plaza-Izurieta, L., Irastorza, I., Elcoroaristizabel, X., Jauregi-Miguel, A., Lopez-Euba, T., Tutau, C., de Pancorbo, M.M., Vitoria, J.C. \& Bilbao, J.R., 2014. Coregulation and modulation of NF- $\mathrm{B}$ related genes in celiac disease: Uncovered aspects of gut mucosal inflammation. Hum Mol. Genet. 23, 1298-1310. DOI: 10.1093/hmg/ddt520

Fietto, J.L.R., Araújo, R.S., Valadão, F.N., Fietto, L.G., Brandão, R.L., Neves, M.J., Gomes, F.C.O., Nicoli, J.R. \& Castro, I.M., 2004. Molecular and physiological comparisons between Saccharomyces cerevisiae and Saccharomyces boulardii. Can. J. Microbiol. 50, 615-621. DOI: 10.1139/w04-050

Gaskins, H.R., Collier, C.T. \& Anderson, D.B., 2002. Antibiotics as growth promotants: Mode of action. Anim. Biotechnol. 13, 29-42. DOI: $10.1081 / \mathrm{ABIO}-120005768$

Hudson, L.E., McDermott, C.D., Stewart, T.P., Hudson, W.H., Rios, D., Fasken, M.B., Corbett, A.H. \& Lamb, T.J., 2016. Characterization of the probiotic yeast Saccharomyces boulardii in the healthy mucosal immune system. PLoS One. 11, e0153351. DOI: 10.1371/journal.pone.0153351

Jiang, Z., Wei, S., Wang, Z., Zhu, C., Hu, S., Zheng, C., Chen, Z., Hu, Y., Wang, L., Ma, X. \& Yang, X., 2015. Effects of different forms of Saccharomyces cerevisiae on growth performance, intestinal development, and systemic immunity in early weaned piglets. J. Anim. Sci. Biotechnol. 6, 47. DOI: 10.1186/s40104-015-0046-8

Kiarie, E., Scott, M., Krause, D.O., Khazanehei, H., Khafipour, E. \& Nyachoti, C.M., 2012. Interactions of Saccharomyces cerevisiae fermentation product and in-feed antibiotic on gastrointestinal and immunological responses in piglets challenged with Escherichia coli K88+1. J. Anim. Sci. 90, 1-3. DOI: 10.2527/jas.52977

Lallès, J.P., Bosi, P., Smidt, H. \& Stokes, C.R., 2007. Nutritional management of gut health in pigs around weaning. Proc. Nutr. Soc. 66, 260-268. DOI: 10.1017/S0029665107005484

Lawrence, T., 2009. The nuclear factor NF-kB pathway in inflammation. Cold Spring Harb. Perspect. Biol. 1 a001651. DOI: 10.1101/cshperspect.a001651

Liu, Y., Espinosa, C.D., Abelilla, J.J., Casas, G.A., Lagos, L.V., Lee, S.A., Kwon, W.B., Mathai, J.K.. Navarro D.M.D.L., Jaworski, N.W. \& Stein, H.H., 2018. Non-antibiotic feed additives in diets for pigs: A review. Anim. Nutr. 4, 113125. DOI: 10.1016/j.aninu.2018.01.007

López- Hernández, R., Valdés, M., Campillo, A., Martínez-García, P., Salama, H., Bolarin, J.M., Martínez, H., MoyaQuiles, M.R., Minguela, A., Sánchez-Torres, A., Botella, C., Salgado, G., Miras, M., Carballo, F. \& Muro, M., 2015. Pro- and anti-inflammatory cytokine gene single-nucleotide polymorphism in inflammatory bowel disease. Int. J. Immunogene. 42, 38-45. DOI: 10.1111/iji.12160

Makkink, C.A., Negulescu, G.P., Qin, G. \& Verstegen, M.W., 1994. Effect of dietary protein source on feed intake, growth, pancreatic enzyme activities and jejunal morphology in newly-weaned piglets. Br. J. Nutr. 72, 353-368. DOI: 10.1079/BJN19940039

Martins, F.S., Dalmasso, G., Arantes, R.M.E., Doye, A., Lemichez, E., Lagadec, P., Imbert, V., Peyron, J-F. Rampal, P., Nicoli, J.R. \& Czerucka, D., 2010. Interaction of Saccharomyces boulardii with Salmonella enterica serovar Typhimurium protects mice and modifies T84 cell response to the infection. PLoS One 5, e8925. DOI: 10.1371/journal.pone.0008925

Martins, F.S., Elian, S.D., Vieira, A.T., Tiago, F.C., Martins, A.K., Silva, F.C.P., Souza, E.L.S., Sousa, L.P., Araújo, H.R.C., Pimenta, P.F., Bonjardim, C.A., Arantes, R.M.E., Teixeira, M.M. \& Nicoli, J.R., 2011. Oral treatment with Saccharomyces cerevisiae strain UFMG 905 modulates immune responses and interferes with signal pathways involved in the activation of inflammation in a murine model of typhoid fever. Int. J. Med. Microbiol. 301, 359-364. DOI: 10.1016/j.jimm.2010.11.002

Martins, F.S., Vieira, A.T., Elian, S.D.A., Arantes, R.M.E., Tiago, F.C.P., Sousa, L.P., Araújo, H.R.C., Pimenta, P.F., Bonjardim, C.A., Nicoli, J.R. \& Teixeira, M.M., 2013. Inhibition of tissue inflammation and bacterial translocation as one of the protective mechanisms of Saccharomyces boulardii against Salmonella infection mice. Microbes Infect. 15, 270-279. DOI: 10.1016/j.micinf.2012.12.007

McCracken, B., Spurlock, M.E., Roos, M.A., Zuckermann, F.A. \& Gaskins, R., 1999. Weaning anorexia may contribute to local inflammation in the piglet small intestine. Biochem. Mol. Act. Nutr. 129, 613-619. DOI: 10.1093/jn/129.3.613

McFarland, L., 2010. Systematic review and meta-analysis of Saccharomyces boulardii in adult patients. World J. Gastroenterol. 16, 2202-2222. DOI: 10.3748/wjg.v16.i18.2202

Nabuurs, M.J.A., Hoogendoorn, A., Van der Molen, E.J. \& Van Osta, A.L.M., 1993. Villus height and crypt depth in weaned and unweaned pigs, reared under various circumstances in the Netherlands. Rest. Vet. Sci. 55, 78-84. DOI: 10.1016/0034-5288(93)90038-H

National Research Council (NRC), 2012. Nutrient requirements of swine. 11th edition. The National Academies Press. Washington DC, USA. Doi.org/10.17226/13298

Naugler, W.E. \& Karin, M., 2013. The wolf in sheep's clothing: The role of interleukin-6 in immunity, inflammation and cancer. Trends Mol. Med. 14, 109-119. DOI: 10.1016/j.molmed.2007.12.007 
Nyachoti, C.M., Omogbenigun, F.O., Rademacher, M. \& Blank, G., 2006. Performance responses and indicators of gastrointestinal health in early-weaned pigs fed low-protein amino acid-supplemented diets. J. Anim. Sci. 85, 125134. DOI: $10.2527 / 2006.841125 x$

Palma, M.L., Zamith, M.D., Martins, F., Bozza, F.A., Nimrichter, L., Montero, L.M., Marques, E.T.A. \& Douradinha, B., 2015. Probiotic Saccharomyces cerevisiae strains as biotherapeutic tools: is there room for improvement? Appl. Microbiol. Biotechnol. 99, 6563-6570. DOI: 10.1007/s00253-015-6776-x

Pérez-Sotelo, L.S., Talavera-Rojas, M., Monroy-Salazar, H.G., Lagunas-Bernabé, S., Cuarón-lbargüengoytia, J.A., Montes de Oca, R. \& Vázquez-Chagoyán, J.C., 2005. In vitro evaluation of the binding capacity of Saccharomyces cerevisiae Sc47 to adhere to the wall of salmonella spp. Rev. Latinoam. Microbiol. 47, 70-75. https://reference.medscape.com/medline/abstract/17061530

Pié, S., Lallès, J.P., Blazy, F., Laffitte, J., Sève, B. \& Oswald, I.P., 2004. Weaning is associated with an upregulation of expression of inflammatory cytokines in the intestine of piglets. J. Nutr. 134, 641-647. DOI: 10.1093/jn/134.3.641

Pothoulakis, C., 2009. Review article: Anti-inflammatory mechanisms of action of Saccharomyces boulardii. Aliment. Pharmacol. Ther. 30, 826-833. DOI: 10.1111/j.1365-2036.2009.04102.x

Rajput, I.R., Li, L.Y., Xin, X., Wu, B.B., Juan, Z.L., Cui, Z.W., Yu, D.Y. \& Li, W.F., 2013. Effect of Saccharomyces boulardii and Bacillus subtilis B10 on intestinal ultrastructure modulation and mucosal immunity development mechanism in broiler chickens. Poult. Sci. 92, 956-965. DOI: 10.3382/ps.2012-02845

Rivera-Zavala, J.B., Molina-Aguilar, C., Pérez- Mendoza, M., Olguín-Martínez, M., Hernández-Muñoz, R., Báez-Ruiz, G.A. \& Díaz-Muñoz, M., 2017. Daytime restricted feeding modifies the daily regulation of fatty acid $\beta$-oxidation and lipoprotein profile in rats. Br. J. Nutr. 117, 930-941. DOI: 10.1017/S0007114517000800

Saavedra, P.G., Vásques, G.M. \& González, L.A., 2011. Interleucina-6: ¿amiga o enemiga? Bases para comprender su utilidad como objetivo terapéutico. latreia. 24, 157-166. http://www.scielo.org.co/pdf/iat/v24n2/v24n2a05.pdf

Sánchez-Muñoz, F., Dominguez-López, A. \& Yamamoto-Furusho, J., 2008. Role of cytokines in inflammatory bowel disease. World J. Gastroenterol. 14, 4280-4288. DOI: 10.3748/wjg.14.4280

SAS Institute, 1994. SAS/STAT User's Guide USA

Sougioultzis, S., Simeonidis, S., Bhaskar, K.R., Che, X., Anton, P.M., Keates, S., Pothoulakis, C. \& Kelly, C.P., 2006. Saccharomyces boulardii produces a soluble anti-inflammatory factor that inhibits NF-KB-mediated IL-8 gene expression. Biochem. Biophys. Res. Commun. 343, 69-76. DOI: 10.1016/j.bbrc.2006.02.080

Steel, R.G.D. \& Torrie, J.H., 1997. Principles and procedures of statistics. A biometrical approach. McGraw Hill, New York, USA

Stein, H.H. \& Kil, D.Y., 2006. Reduced use of antibiotic growth promoters in diets fed to weanling pigs: Dietary tools, part 2. Anim. Biotechnol. 17, 217-231. DOI: 10.1080/10495390600957191

Thacker, P.A., 2013. Alternatives to antibiotics as growth promoters for use in swine production: A review. J. Anim. Sci. Biotechnol. 4, 35. DOI: 10.1186/2049-1891-4-35

Trevisi, P., Colombo, M., Priori, D., Fontanesi, L., Galimberti, G., Calò, G., Motta, V., Latorre, R., Fanelli, F., Mezzullo, M., Pagotto, U., Gherpelli, Y., D'Inca, R. \& Bosi, P., 2015. Comparison of three patterns of feed supplementation with live Saccharomyces cerevisiae yeast on postweaning diarrhea, health status, and blood metabolic profile of susceptible weaning pigs orally challenged with Escherichia coli F4ac. J. Anim. Sci. 93, 2225-2233. DOI: 10.2527/jas2014-8539

Trinchieri, G., Pflanz, S. \& Kastelein, R.A., 2003. The IL-12 family of heterodimeric cytokines: New players in the regulation of T cell responses. Immunity. 19, 641-644. DOI: 10.1016/S1074-7613(03)00296-6

Zanello, G., Meurens, F., Berri, M., Chevaleyre, C., Melo, S., Auclair, E. \& Salmon, H., 2011. Saccharomyces cerevisiae decreases inflammatory responses induced by F4+'enterotoxigenic Escherichia coli in porcine intestinal epithelial cells. Vet. Immunol. Immunopathol. 141, 133-138. DOI: 10.1016/j.vetimm.2011.01.018

Zundler, S. \& Neurath, M.F., 2015. Interleukin-12: Functional activities and implications for disease. Cytokine Growth Factor Rev. 26, 559-568. DOI: 10.1016/j.cytogfr.2015.07.003 